\title{
Gravens By Design: Standards, Competencies and Best Practices for Infant and Family Developmental Care in Intensive Care: The Time Has Come
}

Joy Browne, Ph.D., PCNS, IMH-E(IV)

\section{"As evidence mounts to ensure the quality of care for hospitalized infants, and as families become more central to their baby's caregiving, the time has come for assuring that such data are identified, examined, and standards set for family integration into all aspects of care."}

As evidence mounts to ensure the quality of care for hospitalized infants, and as families become more central to their baby's caregiving, the time has come for assuring that such data are identified, examined, and standards set for family integration into all aspects of care. Neurodevelopmental and family-centered care now have a scientific base, practical application, and, most importantly, humane caregiving approaches that provide a basis for the development and implementation of neuroprotective standards to intensive care.

Excellence in neonatal care has produced remarkable outcomes in both mortality and morbidity, but optimal neurodevelopmental and social and emotional outcomes for the most vulnerable babies remain elusive. We have learned from basic and developmental science that early nurturing and caregiving impact neurophysiologic and epigenetic outcomes; however, these important findings are only beginning to be fully understood by medical professionals and applied to fragile newborns.

Recent advances in neuroprotection and developmental caregiving have provided significant opportunities to enhance early brain development and subsequent neurodevelopmental outcomes, yet applying those findings in intensive care is inconsistent and spotty at best. Without recognizing the available evidence, application to clinical care, and integration into all aspects of medical and nursing policies and procedures, the potential benefits will be lost. Global recognition of the need for guidelines and standards for developmental care has resulted in the publication of the European Foundation for the Care of Newborn Infants (EFCNI) Standards of Care for Newborn Health (https://www.efcni.org/health-topics/ in-hospital/developmental-care/) and the Canadian Guidelines for Developmental Care

(https://extranet.ahsnet.ca/teams/policydocuments/1/clp-neonatology-devcare-developmental-care-hcs-203-01.pdf). Until recently, the United States has not established standards or guidelines for developmental, family-centered care. Instead, various disciplines and organizations have developed their own expectancies and competencies for intensive care developmental care and family-centered care practices (for example, from NIDCAP, OT, PT, Speech and Parent groups).

"In recognizing the need for evidencebased standards, competencies, and practice guidelines for infant and family-centered developmental care, an interprofessional group including representatives from all intensive care practice leading organizations and parents came together in 2015 to begin to determine if evidence for a variety of aspects of developmental care, neuroprotection, and family-centered care warranted identification, development, and publication of standards of care."

In recognizing the need for evidence-based standards, competencies, and practice guidelines for infant and family-centered developmental care, an interprofessional group including representatives from all intensive care practice leading organizations and parents came together in 2015 to begin to determine if evidence for a variety of aspects of developmental care, neuroprotection, and family-centered care warranted identification, development, and publication of standards of care. After review of over 1000 publications, classification of quality of studies, and review by national and international professionals, the Standards, Competencies and Best Practice Guidelines for Infant and Family-Centered Developmental Care (IFCDC) process and articulation were published (1) and made readily available on the web (https://nicudesign.nd.edu/nicu-care-standards/).

Development of the Standards was based on the scientific principles that 1 . Baby is an active participant and the primary focus of caregiving, 2. Family as integral and inseparable from the baby, 3. Neuroprotection of the developing brain; 4. Environmental impact, 5. Infant mental health; and 6 . Individualized care. These principles can be demonstrated in intensive care only with appreciation for the change process and application to the system in which it is integrated.

NEONATOLOGY TODAY is interested in publishing manuscripts from Neonatologists, Fellows, NNPs and those involved in caring for neonates on case studies, research results, hospital news, meeting announcements, and other pertinent topics.

Please submit your manuscript to: LomaLindaPublishingCompany@gmail.com 


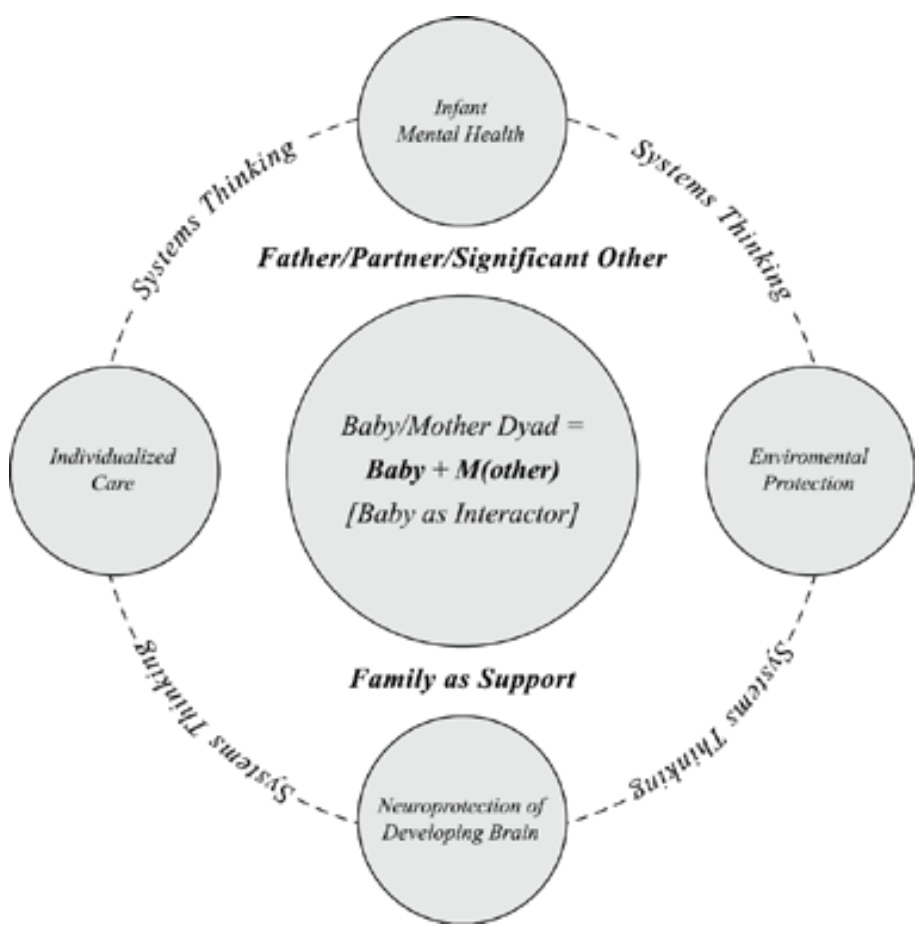

Figure 1 Used with permission

\section{"The evidence is now beyond hearsay and is based on stringent scientific review, so it cannot be relegated to an 'add-on practice when the situation is right."}

The panel additionally identified six content areas that exemplified the aforementioned principles and for which IFCDC is well represented in the literature. The six areas that have ample evidence for the development of standards and competencies for practice include

- $\quad$ Systems Thinking;

- Positioning and Touch;

- $\quad$ Sleep and Arousal;

- $\quad$ Skin-to-Skin Contact with Intimate Family Members;

- $\quad$ Reducing and Managing Pain and Stress in Newborns and Families; and

- $\quad$ Feeding, Eating, and Nutrition Delivery.

IFCDC Standards in each content area include measurable com- petencies, appropriate references, and instruments by which an intensive care professional, administrator, or manager can assess current practice. Additionally, it includes reflective opportunities for improvement of practices, including policy change toward integration into all aspects of intensive caregiving.

The evidence is now beyond hearsay and is based on stringent scientific review, so it cannot be relegated to an "add-on practice when the situation is right."

The panel of professionals agrees that the time has come to become serious about the opportunities that IFCDC affords for optimizing the outcomes of babies and families who experience intensive care at birth, so they not only will survive but thrive. The evidence is based on stringent scientific review, so it cannot be considered "nice but not essential" or an "add-on practice when the situation is right." The IFCDC standards and competencies are readily accessible and should raise a call to action for intensive care professionals, managers, quality assurance administrators, and families alike. More information and resources can be found at the website: (https://nicudesign.nd.edu/nicu-care-standards/).

\section{Reference}

1. Browne JV, Jaeger CB, Kenner C. Executive summary: standards, competencies, and recommended best practices for infant- and family-centered developmental care in the intensive care unit. Journal of perinatology : official journal of the California Perinatal Association. 2020;40(Suppl 1):5-10.

Acknowledgments: The author wishes to acknowledge Dr. Carole Kenner and Dr. Carol Jaeger, who have provided substantial contributions to the development and distribution of the Standards and have provided editorial support for the work reported here.

Disclosures: The author has no relevant disclosures

\section{NT}

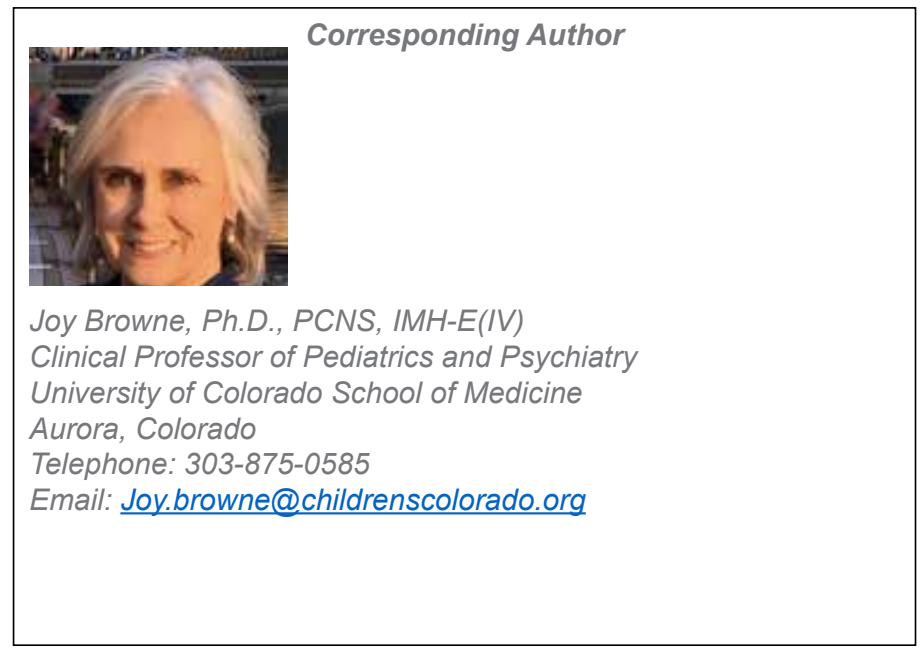

Caring for Babies and their Families: Providing Psychosocial Support to NICU Parents

\section{7- Module Online Course in NICU Staff Education}

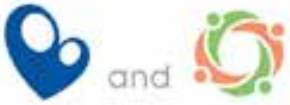

National Perinatal Association and NICU Parent Netwark

mynicunetwork.org 